\title{
Figuras intermediales en Teorema
}

\section{Intermedial Figures in Teorema}

\author{
Wolfgang Bongers \\ Facultad de Letras, Pontificia Universidad Católica de Chile. Santiago, Chile. \\ wolfbongers@gmail.com
}

\section{Resumen}

A partir de los conceptos "intermedialidad" y "remediation", este trabajo quiere destacar y analizar la estética intermedial en la obra de Pasolini, específicamente algunas figuras encontradas en Teorema (libro y película): la "anfibología" como versión moderna de la fórmula horaciana ut pictura poiesis; la forma antiliteraria del texto; el "estilo indirecto libre" en literatura y cine; y a nivel temático de Teorema, la importancia de las artes y los medios técnicos como formas de mediación ente los sujetos burgueses y el mundo. Por otra parte, estas figuras se articulan con la propuesta pasoliniana de pensar el cine como "escritura de la realidad" y forman parte de su proyecto poético-cinematográfico y político-pedagógico en busca de lo sagrado perdido en las sociedades neocapitalistas.

Palabras clave: Pasolini, Teorema, estética intermedial.

\section{Abstract}

Regarding the concepts of "intermediality" and "remediation", this article wants to highlight and analyze the intermedial aesthetics in Pasolini's work, especially some figures found in Teorema (book and film): the "anfibology" as modern versión of the Horacian formula ut pictura poiesis; the antiliterary form of the text; the "free indirect style" in literature and film; and on a thematic level of Teorema, the importance of arts and technical media as forms of mediation between bourgeois subjects and the world. On the other hand, these figures are articulated with Pasolini's proposal of thinking cinema as "writing of reality" and they are part of his poetic-cinematographic and political-pedagogical project in search for the lost sacred in our neocapitalist societies.

Keywords: Pasolini, Teorema, Intermedial aesthetics. 
Teorema nació como si yo lo hubiese pintado con la mano derecha mientras con la izquierda componía un fresco en un gran muro (la película del mismo nombre). En esa índole anfibológica, no sé decir qué parte prevalece: si la cinematográfica o la literaria. A decir verdad, Teorema fue concebido como pieza en verso, hace unos años; después se transmutó en película y, al mismo tiempo, en el relato del cual proviene la película, que a su vez lo corrige. Todo lo cual hace que el mejor modo de leer este manual laico acerca de una irrupción religiosa en el orden de una familia de Milán sea el de seguir los "hechos", la "trama”, deteniéndose lo menos posible en la página. [...] En cuanto al resto, el "estilo indirecto libre" burgués que, queriéndolo o no, he debido extender sobre la urdimbre de la prosa poética, ha acabado por contagiarme hasta darme un leve sentido del humorismo, del desapego, de la mesura [...]: sin embargo, creo que todo ha sido observado y descrito desde un ángulo visual muy extremo, quizá algo amable (no dejo de advertirlo) pero, en compensación, sin alternativas.

P. P. Pasolini, Teorema

Este paratexto ${ }^{1}$ aparece en la contraportada del libro, traducido al español y publicado por Editorial Sudamericana en 1970. Sus palabras dan pistas sobre la creación de Teorema, película y novela estrenada y publicada en Italia en 1968, y esbozan una estética intermedial a la que queremos dedicar las siguientes reflexiones.

Como primera figura intermedial queremos destacar la "anfibología". El concepto denomina una ambigüedad sustancial a nivel verbal (disemia o polisemia) que sugiere interpretaciones diversas y dobles sentidos. Llevado por Pasolini al plano interartístico entre pintura, cine y literatura, esta figura apunta a una indiferenciación e hibridación, un cruce de los registros y medios: pintar el texto y la película, filmar la poesía ${ }^{2}$. Esta

1 Con "paratexto" nos referimos a una de las categorías transtextuales desarrolladas por Genette en Palimpsestos: la literatura en segundo grado (1989) y, más exhaustivamente, en Umbrales (2001). El paratexto considera los bordes y marcos del texto principal, en sus formas peritextuales -lo que acompaña el texto- y epitextuales -lo que se agrega en otros lados o a posteriori-.

2 Esta idea es, también, una variación moderna de la famosa fórmula horaciana ut pictura poiesis, a partir de la cual se genera todo un debate sobre las relaciones y jerarquizaciones entre las artes. Es una formación discursiva en la que Lessing, con su Laocoonte (1766), ocupa un lugar prominente en la historia de las artes, pues allí sostiene la separación tajante entre las artes plásticas y figurativas (artes del espacio) y la literatura/poesía (arte del tiempo). Como Lessing, los defensores de la "pureza" y las especificidades de un arte se olvidan de los inevitables y productivos 
relación cuádruple y dinámica - poesía/pintura/película/relato se intercalan, transmutan y se corrigen- está en el centro de la poética de Teorema y de otras obras de Pier Paolo Pasolini (nombrado alternativamente como PPP en este trabajo). Si asociamos estos procesos de creación con el concepto de "remediation" que proponen Bolter/ Gusin para analizar los diferentes tipos de interacción y transformación entre los medios y las artes, podemos decir que PPP muestra una extraordinaria conciencia de las "literacidades" entre imágenes y textos. Es decir, entre la literacidad de la cultura moderna letrada, herencia de los procesos de la ilustración que se produjeron durante los siglos XVIII y XIX en Europa; y la literacidad de una cultura audiovisual que se instala a nivel mundial a partir del "giro pictórico" (Mitchell) y mecánico en todos los campos del conocimiento y la convivencia social, fenómeno generado en primer lugar por la fotografía a partir de los años cuarenta del siglo XIX y, después, en mayor escala, por el cine a partir de los años veinte del siglo pasado.

Silvestra Mariniello, quien publicó un libro importante sobre PPP en 1999, sostiene en un ensayo más reciente que el concepto de "intermedialidad" da cuenta de ese cambio de paradigma cultural y propone

$$
\begin{aligned}
& \text { pensar la intermedialidad como el conjunto de condiciones que hacen posible } \\
& \text { los cruzamientos y la concurrencia de medios, el conjunto de figuras que los } \\
& \text { medios producen al cruzarse, la disposición potencial de los puntos de una } \\
& \text { figura en relación con los de otra. La intermedialidad es el conocimiento de } \\
& \text { sus condiciones, de la posibilidad de múltiples figuras, de la eventualidad con } \\
& \text { que los puntos de una figura remiten a los de otra. La intermedialidad es tam- } \\
& \text { bién, entonces, un nuevo paradigma que permite comprender las condiciones } \\
& \text { materiales y técnicas de transmisión y de archivo de la experiencia en el pasado } \\
& \text { como en el presente (64). }
\end{aligned}
$$

Por un lado, el concepto describe y nombra las estrategias estéticas de una parte relevante de la producción artística de los últimos decenios; por otro lado, sirve de instrumento analítico para conceptualizar los cruces entre las literacidades modernas que producen obras que ya no corresponden a formas de representación, sino que hacen visibles los procesos de mediación y remediación.

El siguiente fragmento de PPP, en el que describe su paso de novelista a cineasta, refleja el malestar con la literatura como archivo de la literacidad letrada y representacional:

el hecho de sentir que no se puede escribir usando la técnica de la novela se ha transformado inmediatamente en mí, por una especie de auto-terapia inconsciente,

cruces y trasvasijes entre las formas artísticas y sus manifestaciones espaciotemporales, cuyas figuras queremos llamar intermediales. Barthes, Bazin, Bolter/Gusin, Mitchell, Mariniello, Rancière y Speranza son algunos de los críticos que se inscriben en un pensamiento relacional e intermedial, del cual -sostenemos- participa también Pasolini como artista, ensayista y teórico multidimensional. 
en la necesidad de usar otra técnica, o sea, la del cine. [...] Entre mi renuncia a escribir novelas y mi decisión de hacer cinema no ha habido solución de continuidad. Lo he tomado como un cambio de técnica (Empirismo herético189) ${ }^{3}$.

En las primeras páginas del libro Teorema, PPP señala que se trata de un no-relato y que presenta solamente datos e indicaciones. Anuncia, con esto, el fin de la enunciación literaria:

Como el lector ya habrá advertido, el nuestro es, más que un relato, lo que en las ciencias se llama un "informe". Consiste, esencialmente, en una serie de datos. Por lo tanto, su aspecto es el del "código", más que el del "mensaje". Por otro lado, no es realista: al contrario, es emblemático, enigmático... de modo que todo dato preliminar sobre la identidad de los personajes tiene un valor puramente indicativo: sirve a la concreción, no a la sustancia de las cosas (10).

Con esto, el libro corresponde a un género informe $e^{4}$ y antiliterario, una mezcla entre informe técnico, poema, parábola y relato metarreflexivo, consciente de su forma de mediación. En varios pasajes, PPP advierte sobre la artificialidad y la constructividad de la literatura y la participación necesaria del lector como parte activa de esta construcción ${ }^{5}$.

Por otra parte, las reflexiones de PPP acerca de la imagen cinematográfica, presentadas en el contexto de la crítica sesentista sobre la imagen técnica en nuestra cultura y las configuraciones audiovisuales en las "sociedades del espectáculo" (Debord), son singulares y desbordantes en relación a los discursos académicos de esos años (semiología, estructuralismo, postestructuralismo, psicoanálisis y neomarxismo $)^{6}$. En el

3 Cabe mencionar en este contexto el interés de PPP por transmutar -y no adaptar- figuras centrales de la tragedia griega, la Biblia y textos canónicos de la cultura occidental (Decamerón, Tales of Canterbury, Sade) al cine.

4 George Bataille, en el primer número de Documents (1929), habla de "Linforme" como la forma que no tiene forma, una idea que puede asociarse a las intermedialidades e intersticios entre las artes materializados de forma intensa en las vanguardias de esos años.

5 Aquí algunos ejemplos del gesto antiliterario: “Creemos que no será difícil para el lector imaginar cómo viven estas personas, cómo se comportan en sus relaciones con su medio (que es precisamente el de la rica burguesía industrial), cómo actúan en su círculo familiar, etcétera" (7); "Lo repetimos: este no es un relato realista, es una parábola. Por lo demás, todavía no hemos entrado en el núcleo de los acontecimientos, aún estamos en la enunciación” (11); “(¿Esta noche es anterior o posterior al día en que ha ocurrido el encuentro con Emilia? Puede ser anterior o posterior: no tiene la menor importancia)" (16); "Llegado a este punto, el lector deberá resignarse a un difícil y quizá poco agradable desvío desde el curso del relato hasta su fondo, lo cual comporta una interrupción, desde luego árida y prosaica, como todo balance" (88).

6 Notorio es el encuentro entre Barthes, Eco, Metz y Pasolini en el marco de la Mostra Internazionale del Nuovo Cinema en Pesaro, en 1966, época de los nuevos cines políticos y el comienzo de una nueva crítica y teoría cinematográfica. Últimamente, la propuesta de PPP es redescubierta como una fenomenología original de lo visualcinematográfico, alternativa a los análisis lingüísticos del cine; cfr. Dittus. 
ensayo "La lengua escrita de la realidad" (1966), Pasolini sostiene que la realidad no debe entenderse como algo natural sino cultural, siempre mediado por un lenguaje, es decir, por diferentes formas simbólicas y estéticas. El aporte de Pasolini desemboca en el proyecto de una "semiología de la realidad", una variación radical del proyecto de Saussure -la semiología de los signos- y de Barthes - la semiología de la cultura-: el cine es la escritura de una realidad transnacional, universal, frente a la vieja cultura burguesa letrada (Literatura) y la nueva cultura burguesa del espectáculo neocapitalista (televisión) que denuncia Debord.

Este "realismo estético" (Dittus) del cine toma en cuenta la cualidad onírica del medio en los "im-signos", los modos pregramaticales, premorfológicos e inconscientes que operan en el cine. Se trata de una convención estética antes que gramatical, un vocabulario estético propio y no lingüístico que el poeta-cineasta-ensayista elabora en cada filme como manifestación concreta del "cine-lengua". La realidad, en este sentido, es el cine in natura, y la vida es el cine viviente. Mediante la articulación de "cinemas" (equivalentes a fonemas, pero infinitos), el cine-lengua audiovisual opera con unidades de objetos, formas y actos concretos de la realidad (monemas equivalentes a encuadres y planos). Esta filosofía del cine apunta a una inversión del nominalismo - no nomina sunt res sino res sunt nomina- para rematar en que: "La realidad (espiada por el cine) es un conjunto cuya escritura es la estructura de un lenguaje" (Pasolini, Empirismo herético 250).

Este es el punto de partida de las observaciones de Deleuze (La imagen-movimiento) sobre Pasolini, al interpretarlo como un postkantiano cuyo gesto inédito se basa en su concepción del cine no como medio representacional de la realidad, sino como agente que anula la realidad: la imagen cinematográfica es lo real. Deleuze, recurriendo a los textos de Peirce, Bergson y Pasolini, piensa el movimiento y la acción como lenguaje humano que se manifiesta en el cine. Hay ausencia de mímesis: el cine-lengua expresa la realidad por medio de la realidad; la imagen se vuelve idéntica a su modelo.

Las propuestas pasolinianas sobre la literatura y el cine -en diálogo con otros proyectos neovanguardistas en las artes de los años sesenta y setenta- están en sintonía con el postulado epistemológico de la intermedialidad que esbozamos más arriba. Acentúan el paso de la representación del mundo a la manifestación de los procesos de mediación entre sujeto y mundo: la realidad es el lenguaje de múltiples lecturas y discursos ${ }^{7}$. Durante el siglo XX, la literatura se vuelve informe; al mismo tiempo, el cine, en sus formas disidentes, se vuelve revolucionario en sus propuestas de percibir y mostrar la realidad: tiempo y espacio se convierten en elementos objetivables y manipulables, el medio se vuelve intermediario entre lo real y lo imaginario.

7 Esta visión le permite a PPP una reinterpretación de la noción de "mímesis" como apertura a la "pluralidad lingüística y a la contaminación de estilos" (Bentivegna 16). 


\section{III}

Al considerar el realismo estético de PPP, y volviendo brevemente al paratexto de la contratapa de Teorema, queremos destacar otra figura intermedial mencionada aquí: el "estilo indirecto libre". Es un recurso narratológico, utilizado en literatura y cine, que corresponde a la expresión de una semisubjetividad, un estado ambiguo entre estilo directo (monólogo, diálogo) e indirecto (narrador). En su taxonomía de las imágenes cinematográficas, Deleuze recurre a esta idea porque le interesa la imagen-percepción de Pasolini en su carácter de "subjetiva indirecta libre", como expresión de un "Mitsein propiamente cinematográfico" (La imagen-movimiento 111). La "imagen-percepción subjetiva" equivaldría a un discurso directo, la "imagen-percepción objetiva” al discurso indirecto, y la "subjetiva indirecta libre" sería la "enunciación tomada en un enunciado que depende de otra enunciación" (111), lo cual provoca un desdoblamiento del sujeto en el lenguaje y en su relación con el mundo. El cine de poesía de PPP expresa, según Deleuze, la "Forma pura" del cogito cinematográfico, una conciencia autónoma que pretende "hacer sentir la cámara" (113) al espectador.

\section{IV}

En otro orden de cosas, y acercándonos a la trama de Teorema, el proyecto poéticocinematográfico de Pasolini es, también, un proyecto político-pedagógico: el motivo central de Teorema y otras de sus obras es la puesta en escena de la burguesía como enfermedad y una de sus consecuencias más graves: la pérdida de lo sagrado provocada por el sistema capitalista del mercado. Por lo tanto, la obra de PPP se plantea como búsqueda de lo sagrado perdido en figuras y formas de la cultura occidental, entre las que Daniel Link, en el prólogo a una edición ampliada de Pasiones heréticas (2012), que reúne la correspondencia de Pasolini, señala las siguientes: "Narciso, Edipo, lo líquido, la contradicción, el poder devastador de los cuerpos, la cruz, la juventud, la extranjería, el corresponsal (de guerra), el desierto" (6).

El teorema, de acuerdo con PPP, es una proposición que afirma una verdad demostrable; el corolario es su consecuencia o conclusión. Una película con este título se vincularía a un cine matemático, deductivo, que produce encadenamientos formales del pensamiento en la imagen. Deleuze, sin embargo, sostiene que Teorema presenta una deducción problemática, y no teoremática. Partiendo de ahí, la película desarrolla un "problema vivo" cuyo leitmotiv sería: "me acosa una pregunta a la que no puedo responder" (La imagen-tiempo 234). Se trata de algo impensado, un afuera, la exterioridad de una creencia que reúne dos extremos teológicos que polarizan toda la obra de Pasolini: un catolicismo extremo y un ateísmo radical.

En este contexto, las artes y los medios técnicos como formas de mediación de lo (no) sagrado ocupan un espacio relevante entre el libro y la película. Afectados por la 
irrupción del huésped como ángel destructor de la vida de los integrantes de la familia burguesa, hay dos personajes cuyos corolarios se articulan con la mediación técnica y artística: Pedro, el hijo pintor de Pablo, y Odetta, la hija que mira y toma fotografías. Pedro y el huésped miran varias veces un cuadro imaginista de comienzos del siglo XX, en la búsqueda de un puro grafismo minimalista (por primera vez: 23:38-24:40):

El cuadro que los dos muchachos miran tiene colores muy resueltos. Colores puros: si se lo observa con atención, es una red de contornos que dejan superficies libres, triángulos, rectángulos combados, como extendidos sobre una superficie curva: sobre esta superficie se expanden esos colores puros, azul de Prusia, rojo. Puros pero muy discretos, casi en sordina, como velados por una pátina. [...] Algo ingenuo y popular, es decir, infantil, podría hacer pensar en el futurismo ruso, en algún pintor menor, amigo de Eisenstein, de Sklovsky o d e Jakobson, que hubiese trabajado entre Moscú y San Petersburgo; o quizás en Praga, como cubista. [...] Un cuadro gráfico, con superficies coloreadas, construido como una perfecta máquina y tan riguroso que ha reducido la pintura al hueso (Teorema 24).

Podemos asociar esta secuencia con una re-educación de la mirada en el arte, una mirada hacia lo informe, promovida por "los poetas y pintores jóvenes", a los que PPP dedica un poema intercalado que termina así: "Disfruta de tus primeras ingenuas y obstinadas experiencias,/ tímido dinamitero, amo de las noches libres,/ pero recuerda que tú estás aquí sólo para ser odiado,/ para derribar y matar" (27). En este espíritu se juntan los dos jóvenes: “con el placer de repetir cien veces las mismas cosas, orgullosos de su propia rebeldía ante toda tradición, henchidos de una pasión limpia y profunda -que sólo se tiene una vez en la vida- los dos amigos empiezan a hablar de literatura y de pintura" (25). El descubrimiento de la "descomposición descompuesta" 8 en la vanguardia aburguesada será el corolario de Pedro, quien dibuja, desfigurada, la cabeza del huésped. Su búsqueda de lo auténtico en técnicas nuevas lo lleva a crear figuras irreconocibles, transgresivas, en gestos radicales que recuerdan los de Duchamp. En las últimas secuencias observamos sus desesperados intentos autocríticos y autodestructores, la desfiguración de sí mismo, la acción de orinar sobre un cuadro, hasta llegar a hacer una performance en su taller con los ojos vendados, vaciando el mismo acto creativo al someterse a las materialidades y figuraciones que se producen al azar (1:01:08-1:02:38; 1:04:36-1:08:14, 1:10:08-1:12:00).

8 "Esas superficies coloreadas (y espléndidamente desgastadas, como si la materia sobre la cual han sido pintadas fuera un material sublime por su pobreza misma: la pobreza del cartón o del papel barato, que amarillea enseguida); esos contornos precisos, hechos con el solo designio de 'descomponer' la realidad según una técnica entre cubista y futurista (pero en realidad, ni cubista ni futurista del todo), pertenecientes, en suma, a una especie de cultura de la 'descomposición' - pero en verdad, pura y ordenada, como la de los antiguos artesanos, y recuérdese hasta qué punto fueron severas las vanguardias de principios de siglo-: todo esto parece disminuido, envilecido, decepcionante, empobrecido" (68). 
En otra secuencia, Odetta, la hermana neurótica de Pedro, entra en la casa y "vuelve enseguida con su cámara fotográfica, destinada al culto de la familia y del padre: el culto conservador (tantas veces, en el curso de los siglos, confiado a las vírgenes)" (35). Odetta saca y mira las fotografías familiares (33:15-35:20) para el álbum, pero también toma fotos del huésped en el jardín (55:20-56:50): "A través del minúsculo rectángulo del objetivo, lo observa sin ser vista. Mira su rostro, sus hombros, su gran tórax, su breve regazo de joven genitor, su distracción que oculta una violencia de la cual, inocentemente, él no parece darse cuenta, o cuya naturalidad ignora" (35). El objetivo de la cámara le permite ver y desear al huésped, a quien finalmente invita a su cuarto para mirar las fotos de la familia. Al instante, estas fotos se vuelven insignificantes para dar lugar a los cuerpos: "El álbum de las fotografías cae al suelo y las bocas de los dos jóvenes se unen” (37). Más tarde, Odetta mira una fotografía del huésped y "pasa su índice delgado sobre ese cuerpo, como para reconocerlo y acariciarlo a la vez. Es un gesto minucioso, pero incierto y pueril, que sigue torpemente el diseño de la figura fotografiada hasta rozar el regazo. Y en ese instante, de improviso, Odetta cierra la mano y aprieta el puño" (64). La foto del huésped, convertida en parte de su cuerpo por los gestos de Odetta, la atrapa, y es el motivo de su parálisis total.

El huésped -médium de perturbación de la vida burguesa- provoca las desfiguraciones de los dos personajes en las reconfiguraciones artísticas y técnicas que experimentan.

\section{V}

En Teorema hay otras intervenciones y reflexiones acerca de las mediaciones del mundo burgués y sus lenguajes. El discurso periodístico, "lenguaje de baja laya, típico de la cultura para ciudadanos medios" (Teorema 95), aparece en el debate sobre el milagro de Emilia y en las escenas de la entrega de la fábrica de Pablo a los obreros. Es la forma ambigua e informe con la que PPP instala preguntas sobre la relación de la burguesía con la religión y lo sagrado perdido ${ }^{9}$. Con este último gesto

9 Ejemplos: “¿Acaso porque los burgueses no pueden ser verdaderamente religiosos?”/ “¿No en cuanto creen o creen creer, sino en cuanto no poseen un real sentimiento de lo sagrado?"/ "Si suponemos la intervención de un milagro que ponga por fuerza a un burgués en la presencia de lo que es diverso y así le haga dudar de esa falsa idea de sí mismo que ha fundado en la llamada normalidad, ¿podría llegar a adquirir el burgués un genuino sentimiento religioso?”/ “¿No? Por lo tanto, ¿toda experiencia religiosa se reduce, en el burgués, a una experiencia moral?”/ “El moralismo es la religión (cuando existe) de la burguesía?” “De modo que el burgués ha reemplazado el alma por la conciencia?”/ “ ¿Toda antigua situación religiosa se transforma automáticamente, para él, en un simple caso de conciencia?"/ "Entonces ¿es la religión metafísica lo que se ha perdido, transformándose en una especie de religión de la conducta?”/ “¿Cree que éste es el resultado de la industrialización y de la civilización pequeño-burguesa?”/ “De modo que nada, ni siquiera un milagro o una experiencia divina de amor podría resucitar en el burgués ese antiguo sentimiento metafísico de las épocas campesinas? Y en cambio ¿se convertiría para él en una lucha estéril contra su propia conciencia?" [...] "Pero el nuevo tipo de religión que entonces nacerá (y en las naciones más desarrolladas ya se ven los primeros signos) ¿nada tendrá que ver con esta mierda (perdón por la palabra) que es el mundo burgués, capitalista o socialista, en que vivimos?" (88-9). 
intermedial e irónico, Pasolini pone en jaque -desde su prosa poética informe y su cine de poesía- las mediaciones entre sujeto y mundo, en su actualidad dominadas por el espectáculo masivo neocapitalista propio de un mundo desacralizado, para preguntarse y preguntarnos desde una lengua pérfida: “¿La mutación del hombre en pequeño-burgués sería total?” (Teorema 95).

\section{Referencias}

Barthes, Roland. Lo obvio y lo obtuso. Barcelona: Paidós, 2009. Medio impreso. Bazin, André. ¿Qué es el cine? Madrid: Rialp, 2006. Medio impreso.

Bentivegna, Diego. "La Divina Mímesis, un corpus sobreviviente". La Divina Mímesis. Pier Paolo Pasolini. Buenos Aires: El cuenco de plata, 2011. 5-21. Medio impreso.

Bolter, Jay y Gusin, Richard. Remediation. Understanding New Media. MIT Press, 2000. Medio impreso.

Debord, Guy. La sociedad del espectáculo. Buenos Aires: La marca, 1995. Medio impreso.

Deleuze, Gilles. La imagen-movimiento. Estudios sobre cine I. Buenos Aires: Paidós, 2005. Medio impreso.

---. La imagen-tiempo. Estudios sobre cine II. Buenos Aires: Paidós, 2005. Medio impreso.

Dittus, Rubén. "El realismo estético del cine documental en la tesis de Pier Paolo Pasolini”. Aisthesis 53 (2013): 141-157. Medio impreso.

Genette, Gérard. Palimpsestos: la literatura en segundo grado. Madrid: Taurus, 1989.

---. Umbrales. México: Siglo XXI, 2001. Medio impreso.

Mariniello, Silvestra. "Cambiar la tabla de operación. El medium intermedial". Acta poética 30-2 (2009): 59-85. Medio impreso.

Mitchell, William. Picture Theory. Essays on verbal and visual representation. Chicago: University of Chicago Press, 1994. Medio impreso.

Rancière, Jacques. Las distancias del cine. Buenos Aires: Manantial, 2012. Medio impreso. Pasolini, Pier Paolo. Teorema. Buenos Aires: Sudamericana, 1970. Medio impreso.

---. Empirismo herético. Córdoba: Brujas, 2005. Medio impreso.

---. Pasiones heréticas. Buenos Aires: El cuenco de plata, 2012. Medio impreso.

Speranza, Graciela. Fuera de campo. Literatura y arte argentinos después de Duchamp. Barcelona: Anagrama, 2006. Medio impreso. 